\title{
REPRESENTACIÓN Y FIGURACIÓN EN "LA PAZ (BALADA FUTURA)” DE JORGE DEBRAVO
}

\author{
Ronald Campos López
}

\begin{abstract}
RESUMEN
Se analiza el texto debraviano, a partir de los principios teóricos estructurales de López-Casanova, con el fin de perfilar los indicadores poemáticos, el esquema temático, actorialización, modelo compositivo y estructura climática, en el plano de la representación; mientras que las figuras pragmáticas, léxico-semánticas, gramaticales y tónicas, en el plano de la figuración. Se operativiza, así, un ejemplo del esquema metodológico de un poema, cuyo autor perfila una crítica y visión transformadora de los contextos socioculturales de Costa Rica y América Latina, durante la década de los 60.

Palabras clave: Poesía costarricense, Debravo-Jorge, estructuralismo, López-Casanova.
\end{abstract}

\begin{abstract}
This work analyzes A Debravo's (Or Debravian) text from López-Casanova structuralist theoretical principles with the purpose to outline poem indicators, theme scheme, characterization, construction conventions, and climax structure at the representation level. On the other hand, at the imaginary level, it analyzes pragmatic and lexical semantic features from syntax to tonic words. In this way, this study sets forth an example of a methodological approach to a poem, in which the author outlines a criticism and a transforming vision of Latin America and Costa Rica sociocultural contexts during the 60 s.
\end{abstract}

Keywords: Costa Rican poetry, Debravo-Jorge, Structuralism, López-Casanova.

\section{Justificación}

Jorge Debravo ha sido visto como un sujeto dinámico, transformador y representativo de una época, inserto en la cultura costarricense (Brenes 1999, 2007; Rodríguez 2007). Su poesía se orienta en la perspectiva de la función social e identitaria nacional, al proveer una visión liberadora y denunciante de problemáticas socioeconómicas, de dependencia y

Lic. Ronald Campos López. Poeta costarricense. Profesor de secundaria en el Instituto de Educación Integral y de la Universidad Internacional de las Américas.

Correo electrónico: ronaldc184@yahoo.com

Recepción: 18- 01- 2011

Aceptación: 28- 04- 2011 
explotación (Brenes 1999), durante las décadas de los 60 y 70. En consecuencia, su producción poética ha sido catalogada como poesía conversacional de análisis social (Rodríguez, 2006a) o conversacional historizante (Rodríguez 2006b). Desde sus primeros textos, se constituye un modelo estético de poesía social, en tanto formación discursiva en la historia literaria de Costa Rica, caracterizado por el nivel representacional, enunciativo e ideológico (Rodríguez 2007). En este sentido:

[...] su poesía cumple una labor social, ética y humana, fundamentos de la función poética de su texto. La importancia del texto de Debravo radica no sólo en la configuración del lenguaje poético que lo caracteriza, sino en la multiplicidad de su temática social y la concepción revolucionaria que la sustenta. (Brenes 1999: 2)

Los temas de la naturaleza, la sensualidad de la mujer amada, los elementos vitales y engendradores de las fuerzas telúricas, la divinidad; así como el amor espiritual, la fraternidad y confianza en el ser humano, la justicia, el optimismo, la paz, son recurrentes en su poética (Montanaro 2007). Estos últimos se enfocan en contradecir el capitalismo desde una perspectiva humanística, primero, por la búsqueda de la justicia como camino reflexivo contra el desencanto posmoderno; y, segundo, por promover un espacio de la significación ética y cultural centralizada en la otredad (Rodríguez 2007). Su necesidad religiosa desprovista de lo litúrgico y las formas anquilosadas de la fe ofrecen indicios para una nueva construcción teológica (Montanaro 2007; Retana 2006). Grosso modo, podría asegurarse que sus textos dialogan con los contextos socioeconómicos, culturales e históricos de Costa Rica y Latinoamérica, durante la década de los 60, principalmente (Brenes 2007). Por su parte, el dolor y el sufrimiento, redinamizados en un contexto de salvación socialista de los trabajadores, han sido estudiados desde la teoría sociocrítica (Chen 2006).

Sus textos pretenden circunscribir la proyección utópica del futuro, a partir mensajes para las nuevas generaciones (Brenes 1999); esto es, problematizar el medio y buscar soluciones de las relaciones y funciones sociales por medio de la literatura. Así: "La comunicación poética en Debravo conlleva un mensaje que busca modificar la conducta de los otros seres humanos, es por ello que para cumplir con esta función, le llega al receptor con un contenido social" (Brenes 1999), empleando, en ocasiones, un aparato expresivo coloquial y popular. Esta es la situación de Guerrilleros ${ }^{1}$ (1987), en donde algunos de los textos se caracterizan por metaforizar a partir de lazos comunicatorios, con el fin de establecer mensajes-revelaciones en forma de parábolas (Chen 2006).

En síntesis, los textos debravianos se distinguen por su crítica y condena de actitudes desiguales, excluyentes y opresivas del ser humano y, en consecuencia, propone un cambio basado en valores éticos y morales que lleven a un mejoramiento de la sociedad (Brenes 1999, 2007). Desde este punto de vista, se elige el texto "La paz (Balada futura)", del poemario Guerrilleros.

\section{Anotación general de los aspectos teóricos y metodológicos según López-Casanova}

López-Casanova (1994) sistematiza una propuesta estructural sobre el signo estético considerado: poema. Pretende un acercamiento al modelo textual articulado en un doble plano: representación y figuración, en el cual se suscita la interacción de los estratos y formantes del universo imaginario representado en la elocución lírica. Se mencionarán, a continuación, los aspectos por analizar de esta propuesta ${ }^{2}$. 


\title{
2.1. Plano de la representación
}

En cuanto a los indicadores poemáticos, se considera el título como identificador del sujeto poemático, o el motivo temático, en tanto función fática o de contacto, pragmáticoinformativa, o simbólico-alusiva. Así mismo, tiene cabida la tipología poemática. Se enfocan, en el esquema temático, los motivos nucleares y secundarios del tema, así como la articulación de las unidades y subunidades temáticas, sus relaciones y funciones.

Durante el análisis de la actorialización lírica, se observa a los actores poemáticos en tanto componentes funcionales, sustanciales o de rol temático; sus funciones, esquema y procesos actoriales. Se describen, en los modelos compositivos, los esquemas convencionales de los diferentes textos, ya sea lineal, analítico, sintético o simétrico; la presencia de casos complejos y el esquema de base formularia. En la estructura climática, se precisan las líneas de tensión y finales, en términos de clímax y anticlímax, y las fórmulas complejas resultantes de este proceso.

\subsection{Plano de la figuración}

Sobre las figuras pragmáticas, se analizan las estructuras comunicativas y actitudes líricas, en términos de enunciación, apóstrofe, lenguaje de canción; o bien en cuanto a las tácticas de desdoblamiento, como: enunciación encubridora, imagen en el espejo o diálogo interior. Se observan los procesos de escenificación; así mismo, los sujetos modalizadores y las voces, según su función patética, modal o ideológica.

En cuanto a las figuras léxico-semánticas, se estudian los niveles y clases léxicas, las isotopías y tonalidades del sentimiento y la función imaginativa; esta última en términos de fundamento, formas de la imagen y complicación de la estructura externa.

Los procedimientos de reiteración y distribución, las estructuras primarias (los emparejamientos), el dinamismo expresivo y los conjuntos semejantes en ordenación hipotáctica (el paralelismo) o paratáctica (la correlación) son los formantes de la figura gramatical.

La función rítmica en cuanto al factor cuantitativo, intensivo (esquema acentual), tonal (esquema pausal y encabalgamiento) de timbre (rima y material fónico expresivo) constituye la figura rítmica del texto poético. Se analizan también la instrumentación fónica y función simbólica, así como las leyes del versolibrismo.

Respecto de las figuras gráficas, se observan el relieve grafémico (marcas sobre un grafema específico), la metagrafía, supresión de los signos pausales (signos de puntuación), la ideografía lírica, los hipogramas (distribuciones o iteraciones concentradas en la zona del poema) y los blancos o sagrados interestróficos.

\section{El poema}

\author{
-Padre, píntame la paz \\ en la palma de la mano. \\ - La paz es ancha y no cabe \\ en los mapas planetarios. \\ - ¿No ha muerto entonces la paz? 5 \\ ¿Aún habita algún astro? \\ -Hijo, la paz te recorre \\ el corazón como un canto.
}




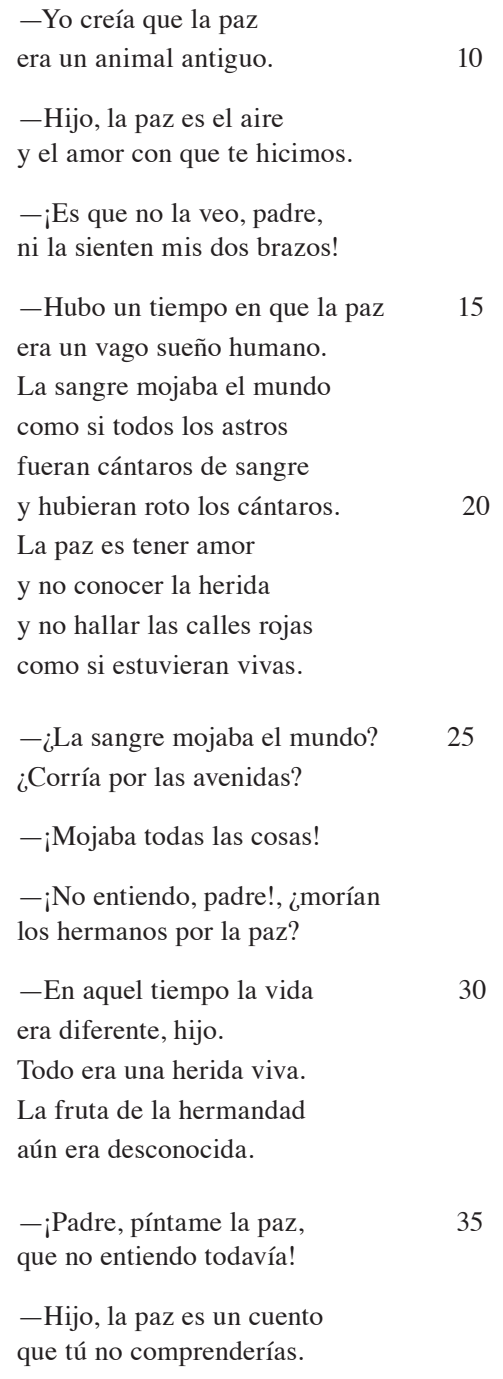

\section{Indicadores poemáticos}

El título de este poema debraviano claramente apunta en su función pragmáticoinformativa hacia un ámbito ideológico y social al establecer el nombre "paz" como motivo temático vivencial, en tanto los actantes poéticos -padre e hijo- conducen el hilo dialéctico alrededor de las experiencias y los conceptos subjetivos. Es el padre quien, a partir de sus percepciones y concepciones sobre la "paz", procede a describirla a su hijo empleando referencias y metáforas, algunas intangibles e incomprensibles para el nivel cognitivo de un niño, según se deduce del diálogo lírico. En el instante cuando el niño no comprende el concepto en juego, el padre precisa una parábola en donde la "paz" se encuentra ausente del entorno social, con tal de rodear un carácter revelativo (Chen 2006), didáctico e ideológico por oposición al tiempo presente en que los actantes se encuentran inmersos.

Por otra parte, el sintagma "balada futura" escrito entre paréntesis como parte del título ofrece también claves de lectura en tanto tipología poética. La balada como tal resulta 
un género más que todo musical, el cual antiguamente se combinaba con la danza, mientras que en la actualidad representa un canto de carácter popular y ritmo lento (RAE 2001). La forma de la balada permite conferir un distinto relieve a las diversas frases y partes del texto; en este caso, el poema debraviano delimita los dos actantes y cada una de sus intervenciones alternativamente en la recitatio poética.

El adjetivo "futura" advierte que la acción lírica o al menos el resultado didáctico de las metáforas y parábolas poetizadas por el padre se comprobará en un tiempo venidero y lejano del presente en el que el lector establece su lectura. Es el tiempo cuando el niño ya haya crecido y asimilado la enseñanza de su padre y promueva, determinativamente, la "paz".

\section{Esquema temático}

Básicamente, en el poema se puede distinguir tres unidades temáticas, las cuales se analizan a continuación.

\subsection{Invocación y petición al padre}

Comprende desde el verso primero hasta el verso 14. En esta sección, el hijo exhorta a su progenitor que le defina y demuestre ("píntame") el significado de la "paz". Este verbo, lúdico y mágico, revela no solo el acto de definición, sino también que el hijo es posiblemente un niño quien pide instrucción al respecto:

-Padre, píntame la paz

en la palma de la mano.

El padre por su parte emplea metáforas o imágenes sugerentes de lo intangible de la "paz" como concepto, dado que para el niño esta no le resulta empíricamente creíble. La "paz" se describe como "ancha", ilimitable, que abarca todo un amplio espacio y es incapaz de demostrarla por medio de referentes de la realidad concreta ("no cabe en los mapas planetarios"), dado que su naturaleza es abstracta, casi al punto de idea platónica. Más adelante, se la describe como "aire", de esta manera se refuerzan las connotaciones abstractas, lo cual conllevará que el padre demuestre el concepto por medio de parábolas-revelación (Chen 2006), como recurso factible para la comprensión de su hijo. Se la define también como un "canto"; es decir, como una sensación o experiencia que el sujeto solo puede reconocer en su espacio interior; de este modo se la homologa a un concepto quizá más cercano a la estructura cognitiva de un niño: el "amor" con que sus padres lo han procreado y lo protegen. Por tanto, nótese el carácter aéreo (abstracto) de las metáforas en torno a la "paz", sustentado en gran medida por la semántica de los verbos y la preferencia por conjugaciones en el tiempo presente del modo indicativo:

\begin{tabular}{|l|l|}
\hline \multirow{4}{*}{ La paz } & es ancha \\
\cline { 2 - 2 } & no cabe en los mapas planetarios \\
\cline { 2 - 2 } & te recorre el corazón como un canto \\
\cline { 2 - 2 } & es el aire y el amor con que te hicimos \\
\hline
\end{tabular}

Sin embargo, el hijo enfatiza en que este es un concepto poco asible a su experiencia. Primero, por medio de las formas de copretérito (RAE 2010) “creía” y "era", especula y define la "paz" como "un animal antiguo"; es decir, como un referente concreto propio de su 
cotidianidad al que pudiera palpar y sentirle su fuerza. La misma forma verbal "era" y el adjetivo "antiguo" sugieren que, a pesar de la concreción de la "paz" como "animal", este es un ser no existente, quizá legendario; por ello, las preguntas que conforman la tercera estrofa, en donde el niño expone su curiosidad y su asombro ante la posible existencia de la "paz", quizá debida a la influencia de fuerzas incomprensibles, lejanas, externas e ineludibles ("astro") para la voluntad del hombre, dejan la significancia o niveles de sugerencia de la imagen aún abiertos:

— ¿No ha muerto entonces la paz?
¿Aún habita algún astro?

De todas formas, el hijo insiste en que la "paz" es incomprendida racionalmente por él, en tanto sus experiencias sensorial y empírica ("veo" y "sienten") le son insuficientes para percibirla de manera impetuosa y vivaz en todo el cuerpo. Esta última acotación puede leerse en "mis dos brazos", sinécdoque de "cuerpo" y "fuerza".

Las limitaciones de comprensión del niño ante el conocimiento por adquirir no se debe a una imposibilidad del lenguaje, sino a la inoperancia de un aprendizaje constructivista significativo. Para Piaget, el desarrollo de la inteligencia de un sujeto se da a medida que se presenta una adaptación de este a su entorno: "Este proceso se origina en las funciones elementales (las percepciones, las sensaciones y la motricidad del organismo primitivo o el embrión) y se lleva a cabo por medio de dos mecanismos: la asimilación, o acción del organismo sobre los objetos que lo rodean, y la acomodación, que debe entenderse como las modificaciones que sufre este como consecuencia de las asimilaciones que efectúa" (Piaget 1983, citado en Méndez 2008: 38). Desde este punto de vista, algunas generalidades del constructivismo son: a) Es imposible conocer directamente la realidad, pues el conocimiento está influido o mediado por el sujeto; b) el conocimiento es correcto o incorrecto según la perspectiva desde donde se sitúe el sujeto; c) el nuevo conocimiento es una invención de un nuevo marco explicativo; d) la verdad es múltiple y dependiente del contexto y e) el conocimiento es una construcción de la experiencia (Méndez 2008).

Obsérvese, por tanto, que, en el poema, el niño se enfrenta con dificultad a la "paz", pues resulta una construcción mediatizada por la figura paterna, quien la define a partir de referentes y vínculos emotivos dependientes de su propio contexto y de las experiencias sentimentales del hijo. Se está pretendiendo, mayormente, un proceso de transferencia o asimilación asociativa del conocimiento (Méndez 2008).

Si bien defiende Ausubel que "lo importante no es si los conocimientos se descubren o se reciben, sino que tengan sentido para el aprendiz" (Méndez 2008: 41), en este poema, la estrategia dialéctica de los sujetos líricos permite que el nuevo conocimiento sea una invención de un nuevo marco explicativo y, por tanto, la generación textual; es decir, la búsqueda del potencial de significancia de la palabra y la imagen poética frente al hecho meramente concreto de la realidad.

\subsection{Parábola del padre}

Esta segunda unidad comprende desde el verso 15 hasta el 34. Ante la incomprensión conceptual de su hijo, el padre procede a ejemplificarle la "paz" por medio de una parábola en donde se habla de un tiempo pasado y acontecimientos caóticos para el ámbito social.

La conjugación en pretérito (RAE 2010) "hubo" introduce esta sección. Las formas en copretérito (RAE 2010) de tres verbos específicamente conducen el hilo narrativo. 
Primeramente, "era", en tanto verbo de estado y atributivo, caracteriza a la "paz" como una meta inalcanzable y esfuerzo inútil ("vago sueño") para los seres en conjunto.

Seguidamente, para el verbo "mojaba" se encuentra el sujeto "sangre", sinécdoque en tanto remite como metonimia al cuerpo humano y a la pérdida de vidas humanas, mientras que como metáfora corresponde al sufrimiento y angustia profundos ante el caos y su propagación por el mundo. El símil reforzador de esta metáfora apunta a que el dolor y caos fueron resultado de una determinación astrológica, detonados repentina e inesperadamente por una fuerza desconocida, impersonalmente expresa en la cláusula: "y hubieran roto los cántaros". No interesa cuál es la fuerza detonante de este caos, sino más bien el resultado con tal de demostrar un estado opuesto al pacífico. Para este punto, se observa una bimembración estrófica, donde su primera semiestrofa corresponde a lo anteriormente dicho; mientras la segunda, inmediatamente define ("La paz es...”) por oposición a aquel estado perturbado. "Herida", por tanto, se homologa en tanto sinécdoque a "sangre", "calles rojas [y] vivas", así como a "mundo", en tanto espacio amplio y ubicación espacial de la acción lírica descrita; de este modo, existe un vínculo directo con la primera semiestrofa. El oxímoron se establece cuando "paz" es homologada a "amor" una vez más en medio de esta gradación dolorosa, incrementada todavía más en las próximas dos estrofas:

$\begin{array}{ll}\text { Hubo un tiempo... } & \begin{array}{l}\text { la sangre } \\ \text { cántaros de sangre } \\ \text { la herida }\end{array} \\ & \\ \text { mojaba } & \text { el mundo } \\ & \text { calles rojas, vivas } \\ & \text { las avenidas } \\ & \text { todas las cosas }\end{array}$

Como parte del proceso didáctico, de nuevo el hijo interroga a su padre. Parece no entender ahora la "paz", sino la actitud de los hombres hacia ella focalizada en el verbo "morían”, prácticamente. Reitera, entonces, el padre su parábola. El sintagma preposicional: "En aquel tiempo" desplaza morfológicamente a "Hubo un tiempo", aunque su función pragmática (Calsamiglia y Tusón 1999) es la misma: introducir la empresa didáctica y un distanciamiento temporal según lo establece el demostrativo "aquel” en relación con el tiempo presente cuando los actantes se encuentran dentro del acto lírico. Por su parte, se sintetiza la gradación descrita anteriormente por medio del nombre "vida", el verbo atributivo en copretérito (RAE 2010) y el sintagma nominal "herida viva"; no obstante, se suma un nuevo elemento y la clave del porqué la "paz" se encontraba ausente de aquel mundo y tiempo pasados:

La fruta de la hermandad

aún era desconocida.

Es aquí cuando la comparación entre "paz" y "amor", planteada dos veces anteriormente, queda clara; pues estas dos experiencias, ya no conceptuales, se sintetizan en "hermandad", de modo que el hijo pueda comprender la cadena con base en sus tempranos conocimientos adquiridos. Esta estrofa comprende así mismo otra bimembración, donde los versos 33 y 34 constituyen el oxímoron clave para comprender la parábola caótica sintetizada en los versos 30, 31 y 32 . 


\subsection{Petición}

Comprende esta última unidad desde los versos 35 hasta el 38. De nuevo, constituye un acto del hijo para que el padre le defina el concepto principal del texto. Nótese acá, en consecuencia, una circularidad del poema, basada en la comprensión insuficiente del niño, durante la segunda unidad del poema.

El padre precisa, posteriormente, la "paz" como "un cuento", lo cual implica que aquella reaparezca como una segunda construcción del lenguaje en otro nivel ficcional distinto de las primeras metáforas. El niño en tanto lector-oyente se ve comprometido a creerle a su padre. Este "cuento" solo podrá ser creído, si se interioriza significativamente y se acepta que las metáforas y parábolas empleadas por el padre son insuficientes, pues no llegan al punto de experimentarse, sentirse o verse; es decir, hasta el momento cuando se objetiven las referencias sensoriales de la realidad, en una estructura racional, cognoscitiva y vivencial cotidiana para el otro.

La apertura de la petición en este poema, en síntesis, resulta el valor principal para la generación del texto, pues las dos noumenotécnicas (Bachelard 1993) de la imaginación simbólica (objetivación científica y expresión poética) fallan y obligan a retornar a la pregunta inaugural, con el fin de autentificar de nuevo el ejercicio de la imaginación creadora.

\section{Actorialización lírica}

Resulta difícil establecer si los dos sujetos líricos pertenecen a una categoría jerárquica o a una horizontalidad igualitaria. No obstante, por ser el hijo quien invoca al padre y le explicita su petición, podría considerarse, en efecto, que existe una categoría mayor y otra menor de acuerdo con aspectos biológico-familiares. Se da, por tanto, una actuación equitativamente válida y alternada entre las dos voces, la clasificación de sujeto y destinador líricos corresponde más a la posición de cada uno de estos actantes en relación con el tema enunciado.

La presentación del sujeto (el padre) se manifiesta a lo largo del poema en las estrofas pares, mientras el destinador (el hijo) interviene en las estrofas impares. Básicamente, la función de la figura paterna es mediar una enseñanza didáctica sobre la "paz", por medio de metáforas y una parábola según las peticiones de su destinador lírico. En primera instancia, este último marca un distanciamiento y una cercanía simultáneos del discurso poético al dirigirse a aquel con el vocativo: "padre". Una distancia en tanto se asume un papel de respeto desde un sujeto menor frente a uno mayor; se establecen así categorías de jerarquía en donde es el padre quien posee la autoridad ante cualquier interrogante y es capaz de brindarle a su hijo las herramientas cognitivas necesarias para comprender cualquier evento, vivencia o concepto. Sin embargo, la cercanía es notoria al mismo tiempo, en tanto el uso del tuteo establece valores de intimidad y proximidad afectiva, gracias al vínculo familiar en este caso (Agüero 2009; Quesada 2009). De este modo, las relaciones del circuito comunicativo entre los actantes se describen de la siguiente manera:

\begin{tabular}{|c|c|}
\hline A1 & A2 \\
\hline SUJETO & DESTINADOR \\
\hline Padre & Hijo \\
\hline Enseña didáctica, metafórica e ideológicamente & Cuestiona y aguarda enseñanza o respuesta alguna \\
\hline
\end{tabular}

En estas relaciones, en donde el padre habla a su hijo con tal de brindarle una enseñanza por medio de reminiscencias del pasado, parábolas o conceptos figurados a fin de completar 
más eficientemente el circuito comunicativo, se remite, como fuente intertextual, a la Biblia; por ejemplo, en Proverbios 13:1, donde se establece la sabiduría de aquel hijo capaz de entender y conservar las enseñanzas de su padre: "El hijo sabio recibe el consejo de su padre; mas el burlador no escucha las reprensiones".

En este mismo libro de Proverbios, se legitiman las enseñanzas del padre para cualquier hijo como fuente de conocimiento. Se pretende que este último debiera conservar y valorar las palabras de su progenitor, ya fuera consejo, ya orden, ya enseñanza, en su vida. Todo conocimiento paterno es incuestionable y heredado en tanto unidireccionalidad, pues es el hijo quien no sabe y debe preguntar, escuchar y aprender de alguien de su propia sangre, sin titubear. Ello se ve reflejado en Proverbios 4:1-27 y 6:23, respectivamente:

Oíd, hijos, la enseñanza de un padre, y estad atentos, para que conozcáis cordura. Porque os doy buena enseñanza; no desamparéis mi ley. Porque yo también fui hijo de mi padre, delicado y único delante de mi madre. Y él me enseñaba y me decía: Retenga tu corazón mis razones, guarda mis mandamientos, y vivirás. Adquiere sabiduría, adquiere inteligencia; no te olvides ni te apartes de las razones de mi boca [...]

Porque el mandamiento es lámpara, y la enseñanza es luz, y camino de vida las reprensiones que te instruyen $[\ldots]$

El hablar del padre o de Dios como Padre a cualquier hijo por medio de parábolas es uno de los mecanismos discursivos y poéticos recurrentes en el texto bíblico, debido a las múltiples interpretaciones que la enseñanza en tanto lenguaje puede alcanzar de acuerdo con las vivencias contingenciales y simbólicas del espectador, con propósitos meramente didácticos e ideológicos. Nótese esto en libros como Ezequiel 17:2: "Hijo de hombre, propón una figura, y compón una parábola a la casa de Israel"; y 24:3: "Y habla por parábola a la casa rebelde, y diles: Así ha dicho Jehová el Señor [...]".

Entre tanto, obsérvese cómo en estas referencias bíblicas predominan la unidireccionalidad de la enseñanza y la parábola, la obligatoriedad del hijo por comprender y obedecerla sin cuestionar argumento alguno, así como la transmisión oral de las enseñanzas de generación en generación. No obstante, en el poema no se comparte el hecho de que el hijo haya comprendido a su padre, ni se comprenden expectativas de que este comparta sus aprendizajes simbólicos con su potencial descendencia. Como se nota en la síntesis estrófica del poema, el hijo reconoce que no ha comprendido las enseñanzas metafóricas y la parábola de su progenitor, así como este reconoce la incapacidad de aprehender una argumentación discursiva, poco empírica, de un concepto abstracto y factible en el ámbito social inmediato a ellos.

\section{Modelos compositivos}

El texto presenta una articulación sintética. La presencia de los dos actantes líricos, más el carácter dialógico del poema, permiten la interacción constante y pausada de cada uno de los sujetos en cuatro procesos: 1) orden-afirmación, 2) cuestionamiento-respuesta, 3) suposición-afirmación y 4) parábola-interrogante/afirmación. De los cuatro procesos, los tres primeros se ubican en la primera unidad del poema, pues estos son los fines comunicativos del hijo hacia su padre. Hasta este momento existe una distribución simétrica de tres pares de estrofas: una recitada por el hijo; otra, por el padre; ambas conforman un diálogo estíquico (Gómez 2007) en forma de dísticos, en los cuales se aprecia: 


\begin{tabular}{|l|l|l|l|}
\hline a.1. imperativo & b.1. interrogante & c.1. suposición & d.1. afirmación \\
\hline a.2. afirmación & b.2. afirmación & c.1. afirmación & \\
\hline
\end{tabular}

Durante la segunda unidad temática, se produce una extensión (parábola) con el fin de proporcionar un mayor entendimiento de los argumentos en juego. Continúa la intervención pareada de los sujetos, con una prolongación en el discurso del padre con fines meramente explicativos. Se desestabiliza en este momento la supuesta simetría del poema para entrar más bien a una argumentación secundaria, propia de la narratio en desarrollo. Las estrategias morfosintácticas determinan las acotaciones:

\begin{tabular}{|l|l|l|}
\hline $\begin{array}{l}\text { e.1. recurrencia parábola } \\
(\text { Hubo...) }\end{array}$ & f.1. afirmación & $\begin{array}{l}\text { g.1 recurrencia parábola } \\
\text { (En aquel tiempo...) }\end{array}$ \\
\hline e.2. interrogante & f.2. interrogante & \\
\hline
\end{tabular}

Nótese que durante la primera unidad temática las afirmaciones van marcando las pautas del diálogo, no en vano son pronunciadas por el padre en tanto definición al concepto en juego (la "paz"); mientras en la segunda parte, corresponde a las interrogantes, pronunciadas por el hijo, en tanto no comprende lo discutido. Además, debe rescatarse que en la recurrente parábola se presenta una bimembración, en donde los primeros versos definen la "paz" por referencias antitéticas y en los segundos por afirmación. De este modo, se encontraría una circularidad interna a la segunda unidad:

\begin{tabular}{|l|l|}
\hline e.1.1. La sangre mojaba el mundo... & g.1.1. Todo era una herida viva. \\
\hline e.1.2. La paz es tener amor... & g.1.1. La fruta de la hermandad... \\
\hline
\end{tabular}

Cuanto se demuestra es la desviación de la construcción estructural del poema o más bien la evolución hacia una síntesis sostenida aún en la intervención estíquica de los sujetos líricos:

\footnotetext{
- ¿Padre, píntame la paz,

que no entiendo todavía!

-Hijo, la paz es un cuento

que tú no comprenderías.
}

En estas últimas estrofas, se conjuga la incomprensión del destinador ante su cuestionamiento y demanda inicial, así como la conclusión del padre ante la posibilidad de un no entendimiento racional, si no es a través de un conocimiento empírico, vivencial y cotidiano. Por su parte, el cuestionamiento y demanda del hijo resaltan gracias al paralelismo y simetría estructural entre las primeras estrofas de la unidad primera y tercera:

$$
\begin{gathered}
\text { vocativo }+ \text { imperativo }+ \text { objeto directo } \\
\text { justificación }
\end{gathered}
$$

\section{Estructura climática}

Se presenta en el poema una tensión lineal que apunta hacia un clímax parcial al terminar la primera unidad temática y, luego, el clímax general durante la culminación de la tercera unidad. El parcial se especifica en cuanto a la incapacidad racional-empírica del hijo 
para comprender la "paz" tal como su padre se la ha descrito. La conjunción coloquial "es que" (Agüero 2009) concluye impetuosamente la exclamación demandante y casi sentenciosa:

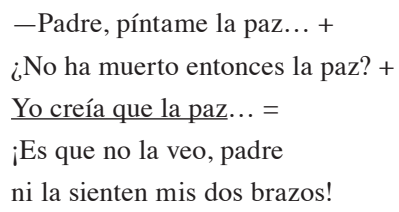

Inmediatamente, se produce el anticlímax, introducido por la parábola relativa a la segunda unidad temática. Las intervenciones planteadas desde los versos 15 hasta el 34 demarcarán, por su parte, una argumentación explicativa, al mismo tiempo que una angustia y cuestionamiento mayores del hijo ante los recursos discursivos, metafóricos y conceptuales empleados por su padre para satisfacer la necesidad inicial. No obstante, todos los esfuerzos realizados a través del texto desencadenan en las justificaciones de los versos 36 ("que no entiendo todavía!") y 38 (“que tú no comprenderías"), introducidos por la conjunción causal y completiva "que" (RAE 2010).

\section{Figuras pragmáticas}

De acuerdo con las actitudes líricas, las relaciones más notorias corresponden a actitudes enunciativas y apostróficas. La primera en tanto que ambos sujetos líricos se refieren o al menos intentan definir la "paz", la cual constituiría la temática lírica; pero, adquiere al mismo tiempo una categoría significativa, tanto como la de un personaje más. De este modo, se cumple una función referencial en tanto se describe la "paz" o es referida como el algo lírico principal a lo largo del texto, hasta el punto de construirse parábolas en torno a ella con tal de conceptualizarla poéticamente.

Por otra parte, la función apelativa se demuestra en tanto el uno como el otro se evocan directamente. El sujeto lírico se refiere al destinatario como "hijo"; mientras este, a aquel como "padre". Ello demarca las posiciones de saber y poder, y desde dónde se pronuncian los argumentos del diálogo poético y desde dónde son escuchados. Por tanto, la tensión comunicativa imaginaria (intratextual) gira en torno a una jerarquía familiar vertical de acuerdo con la edad y la posesión del saber como verdad sobre la realidad misma. Entre tanto, se destacan claramente tres funciones del lenguaje en el texto, las cuales se analizan en las siguientes secciones.

\subsection{Función patética}

Se explicita desde la primera intervención del hijo en la primera estrofa, y luego en la penúltima, su ruego principal; es decir, la definición o demostración tangible de la "paz":

-Padre, píntame la paz

en la palma de la mano.

No obstante, se encuentran otras peticiones expresadas de manera interrogativa al no ser suficientes las argumentaciones en torno a la temática o enfatizar las acotaciones del padre:

- ¿No ha muerto entonces la paz?

¿Aún habita algún astro? 
- ¿La sangre mojaba el mundo?

¿Corría por las avenidas?

- [...] ¿morían

los hermanos por la paz?

\subsection{Función modal}

Únicamente, se precisan dos momentos, ambos expresados por el hijo en tanto supone y afirma no comprender el hecho abstracto de la "paz". En el primer caso, el verbo rige la partícula subordinante, mientras en el segundo, se elide debido al estilo directo empleado:

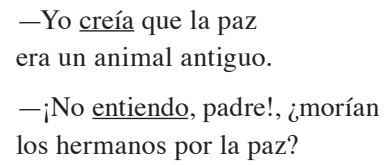

\subsection{Función ideológica}

Los hablantes líricos, en su rol de sujetos modalizadores, apelan al lector por varios medios, los cuales se analizan a continuación.

\subsubsection{Empleo de la parábola}

Esta presupone una comparación intencional al asumir que el pasado en relación con el ahora lírico en que sucede la situación comunicativa imaginaria fue caótico, pues advierte una sociedad y una humanidad agresivas carentes de "paz" y "hermandad". El ahora imaginario del poema sugiere deícticamente un presente dentro de una nueva sociedad antitética a la anterior; por tanto, pacífica, unida, armoniosa y filantrópica. La tensión dramática pretende recrear en el lector una realidad virtual en la medida de lo posible lejana a la realidad que se pretende sea la suya:

-En aquel tiempo la vida

era diferente, hijo.

Todo era una herida viva.

\subsubsection{Metáforas aéreas}

El empleo de metáforas aéreas al poetizar un concepto tan abstracto como la "paz" destacan el carácter de este, de modo que causan en el lector una intangibilidad de ese algo, el cual debiera de algún modo u otro materializarse o ser demostrado en la realidad contingencial y cotidiana, no únicamente en un plano de los ideales:

-La paz es ancha y no cabe

en los mapas planetarios.

- Hijo, la paz es el aire

y el amor con que te hicimos.

\subsubsection{Valores apelados}

La cadena de valores tejida alrededor del concepto principal es clara y demanda al lector su ejecución concreta y experimentación intrapersonales, con el fin de alcanzar esa 
colectividad armoniosa; no en vano corresponde a dos valores primordiales en el ámbito del bienestar individual y social simultáneamente: paz = amor y hermandad.

\section{Figuras léxico-semánticas}

En el poema, se presentan marcas de coloquialismo dado que el texto pretende establecer un diálogo lo más natural posible entre los actantes líricos. La primera corresponde al verbo "píntame", el cual podría asociarse por equivalencia al verbo "dibújame", el cual también es usado popularmente cuando un hablante se refiere a otro deseando que le explique aquello cuanto tratan: "No entendí lo que me estás diciendo, dibujámelo a ver si acaso [...]".

De este modo, las equivalencias semánticas resultan similares, pues las intenciones de los hablantes, tanto el del caso planteado como el lírico, coinciden pragmáticamente. Por otra parte, la conjunción causal "es que" demarca el tono coloquial, pues resulta más empleada en tratamientos populares y cotidianos que en el registro estándar o culto. Por último, el estilo directo con que se hila la recitatio del poema es propio de un discurso coloquial, pues los hablantes se identifican en él, interviniendo alternadamente respecto de la situación.

En el poema, también resulta significativo identificar tres isopatías específicas, dado que estas agrupan resonancias de acuerdo con las intenciones, sentimientos o ideologías propias del yo lírico (extensión imaginaria del poeta en todo caso). La primera isopatía corresponde a los valores demandados y el carácter idealista del concepto principal en juego; de este modo, expresan el fin mismo del poema: paz - aire - sueño - hermandad.

La segunda isopatía corresponde al modo como esta finalidad (la "paz") debería experimentarse; es decir, no constituir una idea o un concepto abstracto, sino hechos verídicos en la realidad cotidiana de una colectividad y de los sujetos en su realidad interior. Por ello, se demanda las sensaciones emotivas y sensoriales: corazón - amor - sienten.

La última demarca por medio de la tensión dramática un estado impactante para el lector al oponer una realidad poetizada al concepto por defender ideológicamente. Dicha agrupación estaría determinada por: sangre - mojaba - herida viva - cántaros rotos - calles rojas - avenidas - morían, pues describen espacio físico, antítesis temática simbólica ("sangre") y propagación del efecto final ("mojaba", "morían”).

De acuerdo con la función imaginativa, se detectan en el poema cuatro realizaciones estéticas conjugadas entre dos planos discursivos y fundamentos objetivos, los cuales se desarrolla a continuación.

\subsection{Símil}

Se aplican estructuras diferentes en cuanto a la comparación de los dos planos en las símiles encontradas en el poema. En el primero, A sustantivo y B sustantivo; mientras en el segundo y tercero, A sustantivo y B cláusula condicional:

\footnotetext{
-Hijo, la paz te recorre

el corazón como un canto.

La sangre mojaba el mundo

como si todos los astros

fueran cántaros de sangre[...]

[...] calles rojas

como si estuvieran vivas.
} 


\subsection{Imagen poética}

Predominan las identificaciones por medio de un verbo copulativo, prácticamente en la definición del concepto principal del poema; así mismo, ocurre con los otros elementos del plano A:

\begin{tabular}{|l|l|}
\hline \multirow{4}{*}{ La paz } & es ancha y no cabe/ en los mapas planetarios. \\
\cline { 2 - 2 } & era un animal antiguo. \\
\cline { 2 - 2 } & era un vago sueño humano. \\
\cline { 2 - 2 } & es un cuento/ que tú no comprenderías. \\
\cline { 2 - 2 } & $\begin{array}{l}\text { es tener amor/ y no conocer la herida/ y no hallar las } \\
\text { calles rojas [...] }\end{array}$ \\
\hline Los astros & fueran cántaros de sangre $[\ldots]$ \\
\hline Todo & era una herida viva. \\
\hline La vida & era diferente. \\
\hline La fruta de la hermandad & aún era desconocida. \\
\hline
\end{tabular}

\subsection{Sinécdoque}

Aparecen dos. Ambas son verbos ("veo" y "sienten"), pues en tanto metonimia forman parte de un conjunto mayor que correspondería a las experiencias sensoriales de un sujeto, y en cuanto a metáfora, a la concreción y realización tangible en el mundo contingente e inmediato de la "paz":

- ¡Es que no la veo, padre,

ni la sienten mis dos brazos!

\subsection{Símbolos arquetípicos}

Los símbolos que en el poema destacan como parte de un repertorio de leit motives debravianos son la "paz", "amor", "hermandad" y la "sangre" como referencia al dolor social, en este caso, y en otras, a la fuerza más intrínseca al ser humano como agente de cambio y vanguardia moral y ética:

- ¿La sangre mojaba el mundo?

- ¡No entiendo, padre!, ¿morían

los hermanos por la paz?

\section{Figuras gramaticales}

Los paralelismos y correlaciones por homosintaxia determinan una intensificación del concepto principal, ya sea por atribuciones copulativas, ya sea cláusulas transitivas, ya sea por antítesis. El primer caso se demuestra con las imágenes poéticas; mientras el segundo, por medio de las referencias del símbolo "sangre" en la parábola de la segunda unidad temática.

La paz (a) es ancha (A1) y no cabe

en los mapas planetarios (A2).

La paz (a) es tener amor (A1)

y no conocer la herida (A2) 


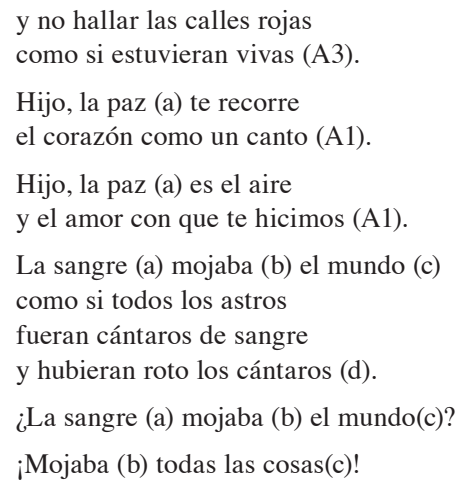

En cuanto a pluralidades o emparejamientos, se encuentran en su mayoría cláusulas unidas por enlace paratáctico mediante la conjunción copulativa "y". Solo en un caso ocurre lo mismo, pero no ya entre cláusulas, sino entre sustantivos como parte de un mismo complemento predicativo:

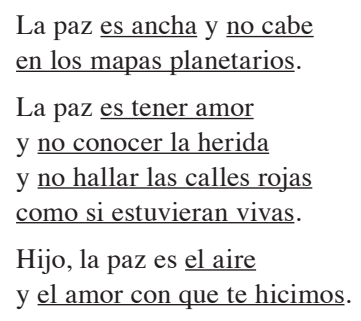

Respecto de los dinamismos expresivos en el poema, demuéstrase uno negativo en tanto la recurrencia a los vocativos, marcadores de pausas mediales, las cuales interrumpen la línea melódica y separan desigualmente los segmentos del verso, así como de las reiteradas preguntas del hijo hacia su padre:

\footnotetext{
-Hijo, la paz es el aire [...]

- ¡Es que no la veo, padre,

ni la sienten mis dos brazos!

- ¿La sangre mojaba el mundo?

¿Corría por las avenidas?

- ¡Mojaba todas las cosas!

- ¡No entiendo, padre!, ¿morían

los hermanos por la paz?
}

Esto permite una intervención pausada de acuerdo con las intenciones de la recitatio; sin embargo, ofrecen un dinamismo lento, negativo, según Bousoño (1985), con tal de enfatizar en la incomprensión conceptual del destinatario lírico hacia el final del texto. Tan solo en un momento del poema se puede detectar un leve dinamismo positivo gracias al empleo de la conjunción copulativa, la cual permite una mayor fluidez en la agrupación de acciones verbales o grupos nominales, como en este caso:

\footnotetext{
La paz es tener amor y no conocer la herida y no hallar las calles rojas como si estuvieran vivas.
} 


\section{Figuras tónicas}

El poema presenta una unidad métrica constante de octosílabos, en donde la distribución acentual predomina en la sílaba séptima en todos los versos; entre los versos segundos y terceros, y entre los versos cuartos y quintos se alternan los acentos, en los cuales, predomina la entonación en los versos segundos y en los cuartos. En otros casos, el primer verso resulta acentuado. Si con estos datos se establece un axis rítmico del poema, diríase entonces que este se define como heteropolar, en tanto la acentuación es irregular y alternada entre los versos 1, 2, 3, 4 y 5, y constante solo en los versos 7:
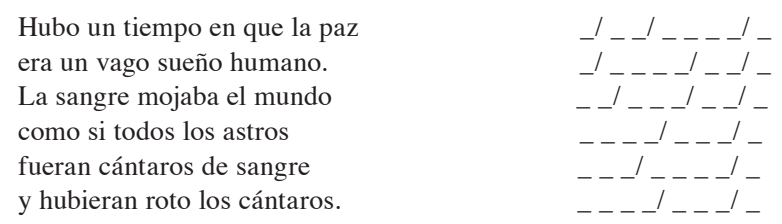

En cuanto a las pausas, el tono general del poema resulta impausado, debido al predominio de las pausas finales en cada uno de los versos. Sin embargo, ocho versos establecen pausas internas, con lo cual un tono agudo (polipausado), en tanto los vocativos de los sujetos líricos ocupan una posición inicial de verso o final, sin repartir equitativamente los segmentos métricos.

Usualmente, podría observarse un desajuste constante entre la unidad de molde métrico y la unidad sintáctica, pues las estructuras de la oración gramatical se ven interrumpidas por la pausa a final de verso; se provoca de este modo un encabalgamiento, distribuido en dísticos, en la mayoría de los casos. No obstante, se encuentran ocho casos en los cuales sí se manifiesta tal correspondencia entre medida métrica y sintaxis (versos 5, 6, 13, 14, 25, 26, 27 y 32).

Respecto de la iteración fónica o aliteraciones, predomina -la más notoria y significativa- la concatenación del fonema consonántico oclusivo bilabial sordo: /p/ (RAE 2011) en el primer verso, con tal de enfatizar profunda y pausadamente también en el sujeto encargado de proveer el conocimiento, la petición hecha por el destinatario lírico y el tema de interés. De este modo, la aliteración funciona como un foco sintético de los elementos más importantes de la recitatio poética ya desde el primer verso. No es de extrañar que sea este verso el introductor de la tercera unidad temática (unidad sintética de acuerdo con el modelo compositivo del texto). En los siguientes casos la sílaba subrayada corresponde a la sílaba acentuada, mientras las consonantes en negrita a los fonemas pertinentes a cada aliteración:

- Padre, píntame la paz

$$
--^{\prime}---{ }^{\prime}-
$$

De todas maneras, pueden encontrarse otras aliteraciones, como la vocal central baja (/a/) en muchos casos, el equilibrio entre nasales sin importar su punto de articulación, así como las vocales posterior alta (/u/) y la posterior media /i/ (RAE 2011):

\footnotetext{
-La paz es ancha y no cabe

en los mapas planetarios.

¿Aún habita algún astro?

¿Corría por las avenidas?
}

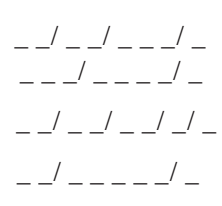

Se puede detectar cuatro momentos cuando el material fónico se encuentra motivado -función simbólica- con tal de producir efectos varios. En el caso de la iteración de la oclusiva 
sorda del primer verso, se enfatiza la petición impetuosa e íntimamente profunda del destinador lírico hacia el sujeto. Durante la segunda estrofa, la aliteración de la vocal central baja (/a/) permite crear una atmósfera de amplitud en cuanto al carácter aéreo (etéreo) del concepto principal en juego. En la novena estrofa, los fonemas sonantes tanto laterales así como nasales (RAE 2011) permiten un efecto de fluidez constante acorde con el sintagma: "La sangre mojaba el mundo [...]". En la última estrofa, la conclusión contundente del padre hacia el hijo se enfatiza por medio de las oclusivas tanto sordas como sonoras: /k/, /t/, /p/, /d/ (RAE 2011).

Por otra parte, las recurrencias fónicas a final de los versos impares determinan en este poema tres series de campos asociativos respecto de los conceptos, definiciones y función ideológica expresos por los actantes líricos. La primera se concentra en torno a la comprobación empírica y sensorial de la "paz" como concepto real (A1 y A6), así como el carácter abstracto de esta en tanto idea (A2 y A3) y, posteriormente, las suposiciones y expectativas de los sujetos líricos en torno a la "paz" (A4, A7 y A8). Esta distribución se visualiza por la correspondencia fónica de la rima asonante /ao/. Por otra parte, el segundo campo asociativo se refiere al caos como antítesis del mundo pacífico, narrado en la parábola donde $\mathrm{C} 1$ y $\mathrm{C} 3$, en tanto referentes del espacio físico caótico, intensificados por $\mathrm{C} 2$, se encuentran más cerca del efecto deponente de C4. Así mismo, C5 se caracterizaría como C6 para el destinador lírico, inclusive para su condición pueril, por lo que C7 entra en estrecha relación con estos dos y la acción potencial de C8. Este segundo gran campo se lee a partir de las correspondencias asonantes de las vocales /ia/. El grupo menor, demarcado por las correspondencias vocales /io/, apuntan hacia los otros dos campos mencionados en tanto B1. Semánticamente, se encuentra más cercano a A; y B2, a C.

\begin{tabular}{|l|c|c|c|}
\hline & A & B & C \\
\hline 1 & mano & antiguos & herida \\
\hline 2 & planetario & hicimos & vivas \\
\hline 3 & astro & & avenidas \\
\hline 4 & canto & & morían \\
\hline 5 & brazos & & vida \\
\hline 6 & humano & & desconocida \\
\hline 7 & cántaros & & todavía \\
\hline 8 & & & comprenderías \\
\hline
\end{tabular}

Por tanto, como se demuestra, en este texto, resulta más fácil determinar funciones eufónico-semánticas antes que funciones temático-gramaticales, pues las correlaciones de las palabras a final de verso no se debe a derivaciones léxicas en común o a formas verbales conjugadas dentro de un mismo tiempo o modo verbal único.

El relieve de las palabras a final de verso se debe a los encabalgamientos simples que predominan en el poema. En su mayoría, separan del verbo y el sujeto a los complementos circunstanciales (a) y oraciones subordinadas adjetivas (b), o al complemento predicativo (c), a veces junto con el verbo copulativo (d). Es durante la segunda unidad temática, donde se encuentran encabalgamientos encadenados, los cuales afectan a cuatro versos seguidos, ya fuera por extensión de la oración subordinada circunstancial (e) o del complemento predicativo (f). En todo caso, se producen coincidencias de sentido, ya descritas anteriormente. 


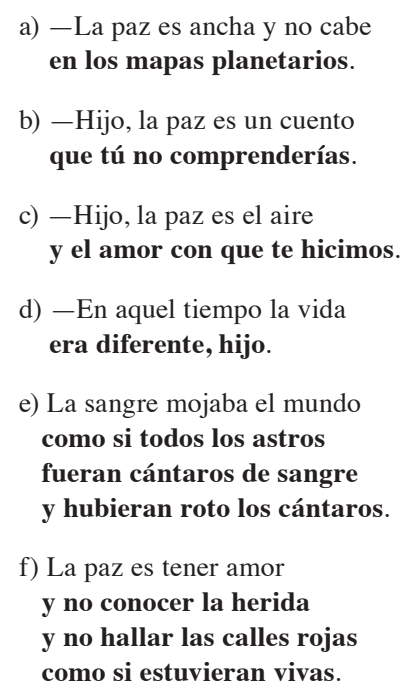

\section{Figuras gráficas}

Para este texto, esta es la figura de menor peso. Solamente, cabe reiterar el hecho de que existen siete estrofas en donde el destinador recita sus inquietudes y siete en donde el sujeto replica. Todas ellas, separadas por blancos interestróficos e identificadas al inicio por un signo pausal (la raya), con el fin de mostrar los valores icónicos del diálogo estíquico.

La distribución en octosílabos permite una imagen igualitaria en longitud en todo el poema, de manera que se informa el hecho de que la palabra de ambos actantes líricos es proporcionalmente significativa en la imagen figurativa del cuadro; pues, a pesar que desde el verso 15 hasta el 24 el sujeto interviene mayoritariamente con su parábola, se concentra en el espacio gráfico del poema, entre catorce versos superiores y catorce inferiores. Esta imagen dividida como un tipo de "brazos cromosómicos" parece reiterarse de manera semejante pero en menor medida, a partir del verso 30 hasta el 35, permitiendo un segmento superior (versos 25-29), focalizado por la incomprensión generadora del texto y las afirmaciones poéticas del padre; y un segmento inferior (versos 36-38), en donde se ubica la conexión cíclica del poema con sus inicios (versos 1, 2, 35 y 36). La longitud y extensión del poema permite visualizar, figurativamente, una cinta adhesiva en sus extremos, pues el "cuento" no acaba ahí.

\section{Conclusiones}

La estructura simétrica y sintética del poema permite desarrollar una recitatio lírica en torno a la definición metafórica y parabólica del concepto de la "paz", por medio de dos actantes líricos quienes interactúan alternativamente. No obstante, dicho concepto no saldrá de la abstracción, en tanto no se manifieste fácticamente en un ámbito social donde predominen los valores del "amor" y la "hermandad" (Brenes 1999, 2007; Rodríguez 2007, 2006a, 2006b; Montanaro 2007). El material fónico, la ascendencia y descendencia climática, así como los símbolos secundarios hilados alrededor de la "paz" desarrollan una ambientalidad envolvente para el lector en la medida que lo capturan en medio de un proyecto lírico ideológico humanístico (Rodríguez 2007), el cual demanda la manifestación concreta y contingente 
primordial para la convivencia humana en un ámbito social utópico y trascendente a todo espacio y tiempo, independientemente al que cada lector pertenezca.

Además, ¿por qué no considerar que ese sujeto lírico sea el poema mismo y ese destinatario, cada lector? A fin de cuentas, la sociedad actual también necesita un diálogo poético para alcanzar su significativa transformación, y el análisis estructural de un asunto poético solamente permite y permitirá, más que un acercamiento, solo una insinuación...

\section{Notas}

1. Guerrilleros consiste en un compendio de poemas inéditos de Jorge Debravo, publicado póstumamente por la Editorial de la Universidad de Costa Rica, en 1987, no en 1995, como sostiene Chen (2006).

2. El texto de López-Casanova resulta claro y conciso en sus planteamientos teórico-metodológicos, de manera que ofrece explicaciones con base en ejemplos textuales. Por tanto, solo se tenderá a describir los aspectos de cada plano durante la segunda parte de este artículo.

\section{Bibliografía}

Agüero, A. 2009. El español del Costa Rica. San José: Editorial UCR.

Bachelard, G. 1993. El aire y los sueños. 6 ${ }^{\text {a }}$ reimpresión. México: Breviarios del FCE.

Bousoño, C. 1985. Teoría de la expresión poética. Madrid: Gredos.

Brenes, M. 2007. "La intertextualidad en la poética de Jorge Debravo". Comunicación, 16: 74-79. http://redalyc.uaemex.mx/pdf/166/16609711.pdf. Consulta: enero de 2011.

1999. "Jorge Debravo hacia el nuevo milenio". Memoria VIII Congreso de Filología, Lingüística y Literatura Carmen Naranjo. Comunicación. http://www.tec.cr/sitios/ Docencia/ciencias_lenguaje/revista_comunicacion/VIII\%20Congreso\%20-\%20 Carmen\%20Naranjo/ponencias/literatura/otrosautores/pdf\%27s/mbrenes.pdf. Consulta: enero de 2011.

Calsamiglia, H. y A. Tusón. 1999. Las cosas del decir. Manual de análisis del discurso. Barcelona: Ariel.

Chen, J. 2006. "Texto cultural y poesía costarricense: Jorge Debravo y Ana Istarú". Káñina, 30 (2): 103-112. http://www.latindex.ucr.ac.cr/kanina-30-2/09-chensham.pdf. Consulta: enero 2011.

Debravo, J. 1987. Guerrilleros. San José: Editorial de la Universidad de Costa Rica.

Gómez, M. 2007. Diccionario Akal de Teatro. Madrid: Akal. 
López-Casanova, A. 1994. El texto poético. Teoría y metodología. Salamanca: Ediciones Colegio de España.

Méndez, V. et al. 2008. Los modelos pedagógicos centrados en el estudiante: Apuntes sobre los procesos de aprendizaje y enseñanza. San José: Vicerrectoría de Investigación, Universidad Estatal a Distancia.

Montanaro, Ó. 2007. “La vigencia poética de Jorge Debravo”. Comunicación, 16: 52-57. http:// redalyc.uaemex.mx/pdf/166/16609708.pdf. Consulta: enero 2011.

Quesada, M. 2009. Historia de la lengua española en Costa Rica. San José: Editorial UCR.

Real Academia Española. 2001. Diccionario de la lengua española. [Versión electrónica]. http://www.rae.es/rae.html

2010. Nueva gramática de la lengua española: Manual. España: Espasa Libros.

2011. Ortografía de la lengua española. Planeta Mexicana.

Retana, E. 2006. “Imágenes liberadoras de Dios en la poesía de Jorge Debravo". Pasos, 125. http://sala.clacso.org.ar/gsdl/cgi-bin/library?e=d-000-00---0pasos--00-0-0Date-0prompt-10---4------0-11--1-es-Zz-1---20-about---00031-001-0-0utfZz-8-0\&a=d\&cl= CL1\&d=HASH0175f81364f731385c52d49d.6. Consulta: enero de 2011.

Rodríguez, F. 2007. “La poesía de Jorge Debravo y el pensamiento humanístico”. Comunicación, 16: 67-73. http://redalyc.uaemex.mx/pdf/166/16609710.pdf. Consulta: enero de 2011.

2006a. "La poesía costarricense contemporánea y el campo discursivo contemporáneo". Káñina, 30 (2): 145-161. http://www.latindex.ucr.ac.cr/kanina-302/14-rodriguezcascante.pdf. Consulta: enero de 2011.

2006b. "La poesía discursiva trascendentalista en la poesía costarricense contemporánea". Revista de Filología y Lingüística, 32 (2): 107-199. http://www. latindex.ucr.ac.cr/filologia-32-2/08-Rodriguez.pdf. Consulta: enero de 2011. 